\title{
Parathyroid Hormone Exerts Disparate Effects on Osteoblast Differentiation Depending on Exposure Time in Rat Osteoblastic Cells
}

\author{
Toshinori Ishizuya, ${ }^{\S}$ Satoshi Yokose, ${ }^{*}$ Masayuki Hori, ${ }^{\S}$ Toshiharu Noda, ${ }^{\S}$ Tatsuo Suda, ${ }^{\ddagger}$ Shusaku Yoshiki, ${ }^{\star}$ \\ and Akira Yamaguchi* \\ *Department of Oral Pathology, and ${ }^{\ddagger}$ Department of Biochemistry, School of Dentistry, Showa University, Tokyo 142, Japan; and ${ }^{\S}$ Laboratory for \\ Bone Metabolism, Life Science Research Institute, Asahi Chemical Industry Co., Ltd., Shizuoka 410-23, Japan
}

\begin{abstract}
It has been reported that PTH exerts bone-forming effects in vivo when administered intermittently. In the present study, the anabolic effects of PTH(1-34) on osteoblast differentiation were examined in vitro. Osteoblastic cells isolated from newborn rat calvaria were cyclically treated with PTH(1-34) for the first few hours of each 48-h incubation cycle. When osteoblastic cells were intermittently exposed to PTH only for the first hour of each 48-h incubation cycle and cultured for the remainder of the cycle without the hormone, osteoblast differentiation was inhibited by suppressing alkaline phosphatase activity, bone nodule formation, and mRNA expression of alkaline phosphatase, osteocalcin, and PTH/PTHrP receptor. Experiments using inhibitors and stimulators of cAMP/protein kinase $\mathrm{A}$ (PKA) and $\mathrm{Ca}^{2+} / \mathrm{PKC}$ demonstrated that $\mathrm{CAMP/PKA}$ was the major signal transduction system in the inhibitory action of PTH. In contrast, the intermittent exposure to PTH for the first $6 \mathrm{~h}$ of each 48-h cycle stimulated osteoblast differentiation. Both cAMP/ PKA and $\mathrm{Ca}^{2+} / \mathrm{PKC}$ systems appeared to be involved cooperatively in this anabolic effect. Continuous exposure to PTH during the 48-h incubation cycle strongly inhibited osteoblast differentiation. Although both cAMP/PKA and $\mathrm{Ca}^{2+} / \mathrm{PKC}$ were involved in the effect of continuous exposure to PTH, they appeared to act independently. A neutralizing antibody against IGF-I blocked the stimulatory effect on alkaline phosphatase activity and the expression of osteocalcin mRNA induced by the 6-h intermittent exposure. The inhibitory effect induced by the 1-h intermittent exposure was not affected by anti-IGF-I antibody. These results suggest that PTH has diverse effects on osteoblast differentiation depending on the exposure time in vitro mediated through different signal transduction systems. These in vitro findings explain at least in part the in vivo action of
\end{abstract}

Part of this work was presented at the 14th Japanese Congress on Bone Morphometry in Akita, Japan on 7 July 1994.

Address correspondence to Akira Yamaguchi, Department of Oral Pathology, School of Dentistry, Showa University, 1-5-8 Hatanodai, Shinagawa-ku, Tokyo 142, Japan. Phone: 81-3-3784-8169; FAX: 81-3-3784-2870; E-mail: akirayam@dent.showa-u.ac.jp. Satoshi Yokose's current address is Department of Operative Dentistry, School of Dentistry, Meikai University, Saitama 350-02, Japan.

Received for publication 9 September 1996 and accepted in revised form 19 March 1997.

J. Clin. Invest.

(C) The American Society for Clinical Investigation, Inc.

0021-9738/97/06/2961/10 \$2.00

Volume 99, Number 12, June 1997, 2961-2970
PTH that varies with the mode of administration. (J. Clin. Invest. 1997. 99:2961-2970.) Key words: parathyroid hormone • osteoblasts $\bullet$ cell culture $\bullet$ protein kinase $\mathrm{A} \cdot$ protein kinase $\mathrm{C}$

\section{Introduction}

In 1929, 4 yr after the discovery of parathyroid hormone, Bauer et al. (1) reported for the first time that subcutaneous injection of parathyroid extract stimulated bone formation in rats. In 1976, Reeve et al. (2) attempted clinical application of the synthetic fragment of human PTH (PTH(1-34)), in which they found an anabolic effect of the hormone in four patients with postmenopausal osteoporosis. To date, a number of in vivo trials have been conducted to explore the anabolic effect of PTH in bone metabolism (3-7). Among these, experiments using intact and osteopenic animals have demonstrated that intermittent administration of PTH increases bone mass, whereas continuous infusion causes a decrease (8-10). The increase in bone mass by the intermittent administration was associated with the parameters of elevated bone formation analyzed by bone histomorphometry. Continuous infusion of PTH caused osteopenia, probably due to greater acceleration of bone resorption than bone formation. Thus, PTH has diverse effects on bone depending on the mode of administration. This suggests that PTH may be useful for the treatment of metabolic bone diseases such as osteoporosis by an appropriate administration, but the mechanisms of the diverse actions or the hormone on bone remain obscure.

Several in vitro culture systems of osteoblastic cells have been available for studying the mechanism of osteoblast differentiation $(11,12)$. Of these, clonal osteoblastic cell lines are useful tools for investigating osteoblast differentiation (13-16). These cells are composed of a relatively homogenous population of osteoblastic cells, but express intrinsic properties reflecting specific stages of osteoblast differentiation. Another useful culture system is primary osteoblastic cells isolated from bone by sequential enzyme digestion $(13,17,18)$. Although these cells are composed of heterogeneous cell populations, they express various osteoblast phenotypes, including the ability to form bone nodules in vitro, and are useful for examining sequential changes of phenotypes occurring during osteoblast differentiation. Using these culture systems, it has become possible to examine the direct effects of various hormones and growth factors on osteoblast differentiation.

A number of in vitro trials have been conducted to investigate the mechanism of action of PTH on proliferation and differentiation of osteoblasts using in vitro culture systems, but the results obtained are inconsistent. For example, PTH stimulated proliferation of primary osteoblastic cells isolated from human trabeculae (19) and from chick calvariae (20), but inhibited proliferation of the rat osteoblastic cell line UMR-106 
$(21,22)$. PTH suppressed alkaline phosphatase (ALP) $)^{1}$ activity in the rat osteoblastic cell line ROS-17/2.8 (23), but had a stimulatory effect in the mouse osteoblastic cell line MC3T3-E1 (24). The hormone strongly inhibited bone nodule formation by primary osteoblastic cells isolated from calvariae of rat embryos (25). In addition, several research groups including ourselves have reported that PTH exerted diverse effects on osteoblast differentiation depending on differentiation stage (26-28). These observations indicate that the action of PTH on osteoblasts varies with cell type and experimental conditions. In most in vitro experiments reported to date, PTH was present during the entire culture period. These experimental conditions, in which PTH was continuously exposed to the cells, appeared to be inappropriate for elucidating the anabolic effect of PTH on bone formation in vitro.

PTH stimulates multiple intracellular signal pathways, including those mediated by cAMP, inositol phosphates, and calcium, and activates both protein kinase $\mathrm{A}$ (PKA) and $\mathrm{C}$ (PKC). Although the multiple signaling stimulated by PTH seems to be closely related to the diversity of PTH effects, the roles of each signal transduction system in osteoblast proliferation and differentiation are not fully understood.

In the present study, the effects of PTH on osteoblast differentiation were examined by treating osteoblastic cells isolated from newborn rat calvariae with $\mathrm{PTH}(1-34)$ continuously or intermittently. We demonstrate here that, when osteoblastic cells were exposed to PTH continuously, the hormone always inhibited osteoblast differentiation, but when the cells were treated intermittently with PTH, it exerted an anabolic effect on osteoblast differentiation depending on the timing of exposure. These in vitro findings explain at least in part the in vivo action of PTH that varies with the mode of administration.

\section{Methods}

Chemicals. PTH(1-34) was synthesized by Asahi Chemical Industry (Shizuoka, Japan). The stock solution of the hormone was dissolved in $4 \mathrm{mM}$ hydrochloride containing $0.1 \%$ bovine serum albumin and stored at $-20^{\circ} \mathrm{C}$. Stock solutions of phorbol myristate acetate (PMA; Research Biochemicals, Inc., Natick, MA) and forskolin (Wako Pure Chemical Industries, Osaka, Japan) were made by dissolving in ethanol. Staurosporin (Wako Pure Chemical Industries) was dissolved in methanol. Adenosine-3',5'-cyclicmonophosphothioate, Rp-isomer (Rp-cAMPS) (Biolog Life Science Institute, Bremen, Germany) was dissolved in alpha-modified minimum essential medium $(\alpha$-MEM; Gibco Laboratories, Grand Island, NY) containing 10\% fetal calf serum. Mouse anti-human IGF-I antibody was purchased from Upstate Biotechnology Inc. (Lake Placid, NY).

Isolation and cell culture of osteoblastic cells. Osteoblastic cells were isolated from calvariae of 1-d-old Sprague-Dawley rats by sequential enzymatic digestion as described previously (29). Briefly, calvariae were minced and incubated at room temperature for 20 min with gentle shaking in an enzymatic solution containing $0.1 \%$ collagenase, $0.05 \%$ trypsin, and $4 \mathrm{mM} \mathrm{Na}_{2}$ EDTA in calcium and magnesium-free phosphate buffered saline (PBS $(-))$. This procedure was repeated to yield a total of six digests. The cells isolated from the last four to six digests were cultured separately in $\alpha$-MEM containing $10 \%$ FCS and antibiotics $(100 \mathrm{mg} / \mathrm{ml}$ of penicillin $\mathrm{G}$ and $100 \mathrm{IU} / \mathrm{ml}$ of streptomycin). After reaching a subconfluent state (80-90\% confluent), the cells were removed from each flask and combined together as osteoblastic

1. Abbreviations used in this paper: ALP, alkaline phosphatase; PKA (or C), protein kinase A (or C). cells. Cells were used for all experiments at the second passage as described below. They were cultured in $\alpha$-MEM containing $10 \%$ FCS, 5 $\mathrm{mM} \beta$-glycerophosphate, $50 \mu \mathrm{g} / \mathrm{ml}$ ascorbic acid, and antibiotics. Since preliminary experiments suggested that the magnitude of the effects on ALP activity induced by various modes of PTH exposure varied between the lots of FCS, we selected a suitable lot of FCS (A0901; Gibco Laboratories), which retained the highest stimulatory effect on ALP activity after 6-h intermittent exposures were repeated four times.

Experimental protocol for PTH exposure. Osteoblastic cells were inoculated at a density of $3.8 \times 10^{3}$ cells $/ \mathrm{cm}^{2}$ and cultured for $16 \mathrm{~h}$ in the absence of PTH(1-34). Then they were divided into three groups according to the mode of exposure to PTH: intermittent exposure group, continuous exposure group, and vehicle-treated group. In the intermittent exposure group, the cells were exposed to $\mathrm{PTH}(1-34)$ for the first $1,3,6$, or $24 \mathrm{~h}$ of each 48 -h incubation cycle, and then cultured in the absence of PTH during the remainder of the cycle. In the continuous exposure group, the cells were exposed to PTH(1-34) from day 1 to the end of the culture period. During this period, the culture medium was changed every $48 \mathrm{~h}$. In the control group, the culture medium containing vehicle was also changed every $48 \mathrm{~h}$.

Measurement of immunoreactive PTH. To estimate the degradation of $\mathrm{PTH}(1-34)$ during culture, osteoblastic cells at a postconfluent state were incubated with culture medium containing 10\% FCS and $50 \mathrm{ng} / \mathrm{ml} \mathrm{PTH}(1-34)$; then the amount of PTH(1-34) in the culture media was determined using an IRMA kit for rat PTH (Immutopics, Inc., CA) at various time points during the 72-h incubation period. Preliminary experiments revealed that the standard curve of human PTH(1-34) using this assay kit was linear $(\mathrm{y}=507.089+11.337 \times$, $r=0.9999)$ from $0-\sim 1,000 \mathrm{pg} / \mathrm{ml}$. The amount of human PTH(1-34) in the culture media was calculated from this standard curve. The amounts of immunoreactive PTH in the culture medium containing $10 \%$ FCS without human PTH(1-34) were $9.07 \mathrm{pg} / \mathrm{ml}$.

Histochemistry. The cells were fixed with $10 \%$ neutral buffered formalin in PBS for $20 \mathrm{~min}$. ALP activity in the cells was determined histochemically using naphthol AS-MX phosphate (Sigma Chemical Co., St. Louis, MO) as a substrate, and fast red violet LB salt (Sigma Chemical Co.) was identified as a coupler as described previously (30). After staining for ALP activity, mineralized bone nodules were detected by von Kossa's staining. To quantify the mineralized bone nodules, the number of black or brown nodules on von Kossa's staining were counted in each well of 6-well plates.

Measurement of ALP activity and calcium content. The cultured osteoblastic cells were sonicated in $0.1 \mathrm{M}$ Tris buffer, $\mathrm{pH} 7.2$, containing $0.1 \%$ Triton $\mathrm{X}-100$. ALP activity was determined using $p$-nitrophenylphosphate as a substrate in $0.05 \mathrm{M}$ 2-amino-2-methylpropanol and $2 \mathrm{mM} \mathrm{MgCl}_{2}, \mathrm{pH} 10.5$. The amount of $p$-nitrophenol released was estimated by measuring absorbance at $410 \mathrm{~nm}$. Protein concentration was determined using BCA protein assay reagent (Pierce Chemical Co., Rockford, IL). The remainders of the sonicated samples used for ALP measurement were incubated with a half volume of $12 \mathrm{~N}$ hydrochloride for $16 \mathrm{~h}$ at room temperature. After centrifugation for 10 min at $6,000 \mathrm{~g}$, the amount of calcium in the supernatant was determined using a calcium C-Test kit (Wako Pure Chemical Industries).

Northern blot analysis and reverse transcription-PCR. Total cellular RNA was extracted from osteoblastic cells using a RNaid PLUS kit (Bio 101 Inc., La Jolla, CA). $20 \mu \mathrm{g}$ total RNA were electrophoresed in $1.2 \%$ agarose-formaldehyde gels, and RNA was transferred on nylon membrane filters (Hybond-N; Amersham International, Little Chalfont, UK). The membranes were hybridized for $2 \mathrm{~h}$ at $65^{\circ} \mathrm{C}$ with $\left[{ }^{32} \mathrm{P}\right]$-labeled cDNA probes for rat ALP, rat osteocalcin, rat procollagen $\alpha 1(\mathrm{I})$, rat PTH/PTHrP receptor, and rat $\beta$-tubulin, which were labeled using a multirandom primer oligonucleotide labeling kit (Boehringer, Mannheim, Germany) and $\left[{ }^{32} \mathrm{P}\right] \mathrm{dCTP}$ (Amersham International) according to the manufacturer's protocol. The relative expression levels of each signal on the hybridized membranes were calculated by BAStation 3000, and the membranes were also processed for autoradiography. 
Complementary DNA was synthesized using SuperScript reverse transcriptase (Takara Shuzo Co., Osaka, Japan) with oligo dT, and it was amplified at the total volume of $50 \mu \mathrm{l}$ by SUPERSCRIPT Preamplification System kit (GIBCO BRL, Gaithersburg, MD). The oligonucleotides for rat osteocalcin were as follows: 5'-CCTCATCTGGACTTTATTTT-3' (3'-primer complementary to nucleotides 461-480) and 5'-GAACAGACAAGATCCCACACA-3' (5'-primer complementary to nucleotides 1-20). The oligonucleotides for rat glyceraldehyde 3-phosphate dehydrogenase (G3PDH) were as follows: 5'-ACCACAGTCCATGCCATCAC-3' (5' primer) and 5'-TCCACCACCCTGTTGCTGTA-3' (3' primer). A total of 30 cycles of amplification was performed with Takara PCR Thermal Cycler MP (Takara Shuzo Co.) at $94^{\circ} \mathrm{C}$ for $30 \mathrm{~s}$, at $65^{\circ} \mathrm{C}$ for $20-30 \mathrm{~s}$, and at $72^{\circ} \mathrm{C}$ for $2 \mathrm{~min}$. Preliminary experiments proved that the PCR conditions employed were within the exponential phase of the amplification curve. The PCR products were electrophoresed in a $1 \%$ agarose gel, and the specificity was confirmed by Southern blot. The PCR products transferred on nylon membrane filters (Hybond-N+ membrane) were hybridized with digoxigenin-labeled internal cDNA probes.

Statistical analysis. The results are expressed as means \pm SD. Statistical analysis between the two groups was performed with Student's $t$ test, and that between the multiple groups was performed with Dunnett test.

\section{Results}

Effects of PTH on osteoblast differentiation depending on mode of exposure. Fig. 1 summarizes the effects of PTH (50 $\mathrm{ng} / \mathrm{ml}$ ) on the formation of bone nodules after repeating eight times the intermittent or continuous exposure to the hormone in each 48-h incubation cycle. Numerous bone nodules that were comprised of ALP-positive cells and mineralized matrices were found in the control cultures by day 17 (Fig. $1 a$ ). PTH induced different effects on the number of bone nodules depending on the exposure time during the 48-h incubation cycle (Fig. 1, $b-f$ ). The number of bone nodules in the 1-h exposure group (Fig. $1 b$ ) was smaller than that in the control group, but larger in the 6-h exposure group (Fig. $1 d$ ). In both the 3- and 24-h exposure groups (Fig. 1, $c$ and $e$ ), the numbers of bone nodules were almost identical to that in the control group. In the continuously exposed group, the number of bone nodules was markedly reduced (Fig. $1 f$ ).

To investigate further the effects of exposure time of PTH $(50 \mathrm{ng} / \mathrm{ml})$ in each 48-h incubation cycle, ALP activity, calcium content in the cell layer, and the number of mineralized bone nodules were quantified (Fig. 2). Intermittent PTH exposure induced diverse effects on the phenotypes of osteoblastic cells depending on the exposure time. The 1-h exposure group showed significant reductions in ALP activity, calcium content, and the number of mineralized bone nodules compared with those in the control group. In contrast, the 6-h exposure induced significant increases in these parameters. In both the 3and 24-h exposure groups, these parameters were almost identical to those in the control group. Continuous exposure strongly reduced ALP activity, calcium content, and the number of mineralized bone nodules.

Fig. 3 summarizes the time courses of changes in ALP activity and calcium content induced by 1 - and 6-h intermittent exposure and continuous exposure to PTH (50 ng/ml). ALP activity increased time dependently in the control culture (Fig. 3 A). The cells intermittently exposed to PTH for $1 \mathrm{~h}$ showed a lower ALP activity than that in the control group on day 5, and continued to express lower ALP activities up to the end of the culture. By contrast, an intermittent 6-h exposure resulted in a definite increase in the enzyme activity relative to the control group on days 5, 9, 13, and 17. Continuous exposure reduced ALP activity significantly compared with the control group during the entire culture period examined. Fig. $3 B$ summarizes the time course of changes in calcium content in the cell layer. In the control culture, amounts of calcium accumulated in the cell layer became measurable on day 13 , and increased up to the end of the culture. Intermittent 1-h exposure gener-

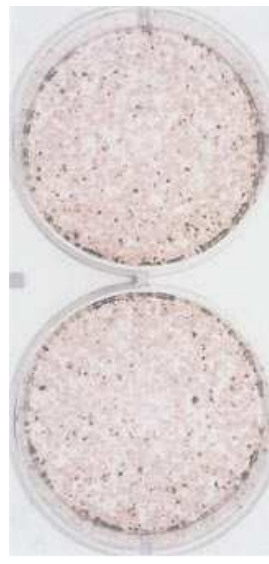

a

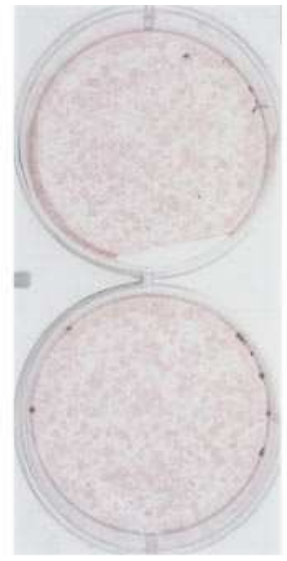

b

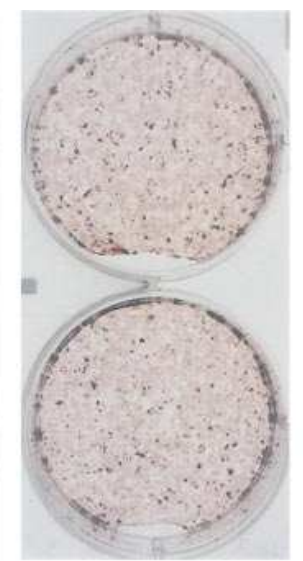

c
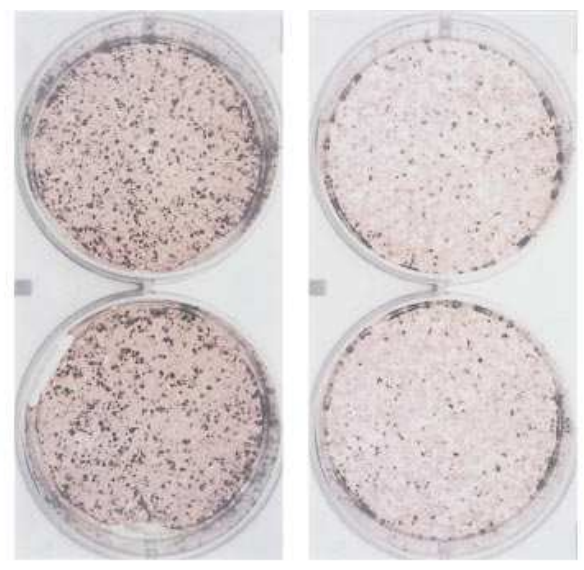

e

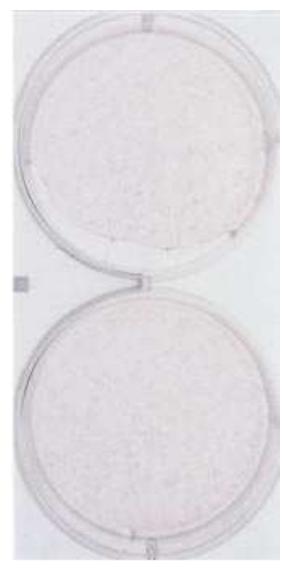

f

Figure 1. Effects of the intermittent and continuous exposure to PTH on the formation of bone nodules. Osteoblastic cells were inoculated in a well of 6-well plates and exposed to PTH intermittently or continuously after preculture for $16 \mathrm{~h}$. In the intermittent exposure group $(b-e)$, cells were exposed to $50 \mathrm{ng} / \mathrm{ml}$ of PTH for the first $1(b), 3(c), 6(d)$, and $24(e) \mathrm{h}$ of each 48 -h incubation cycle, and then cultured in the absence of PTH during the remainder of the cycle. This cycle was repeated eight times, and then the cells were fixed and stained for ALP and von Kossa as described in Methods. The pink shows ALP activity and the small black dots represent mineralized bone nodules. In the continuous exposure group $(f)$, the cells were exposed to $50 \mathrm{ng} / \mathrm{ml}$ of PTH from days 1 to 17 . During this culture period, culture medium was changed every $48 \mathrm{~h}$. In the control group (a), the culture medium containing vehicle was also changed every $48 \mathrm{~h}$. 

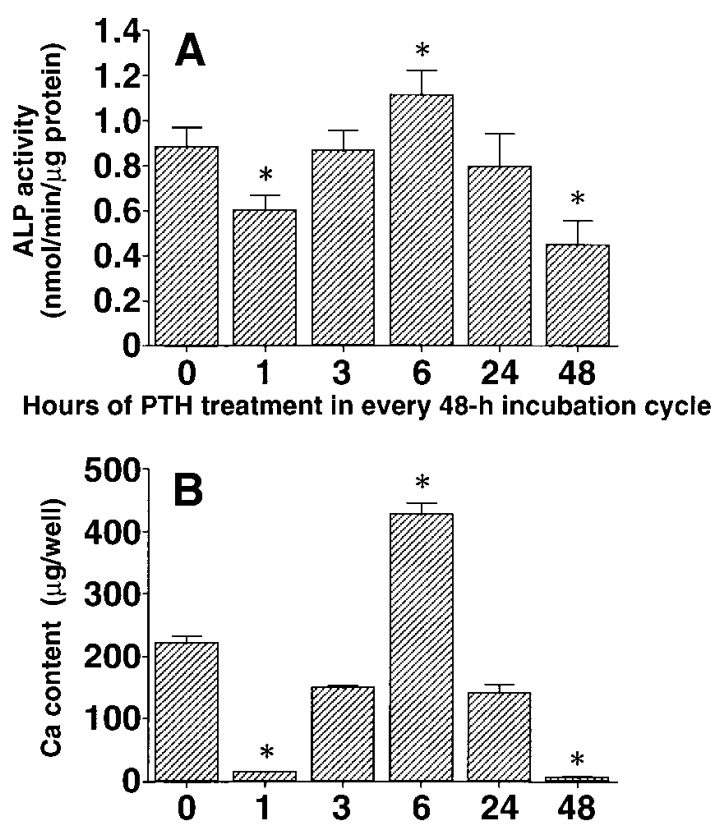

Hours of PTH treatment in every 48-h incubation cycle

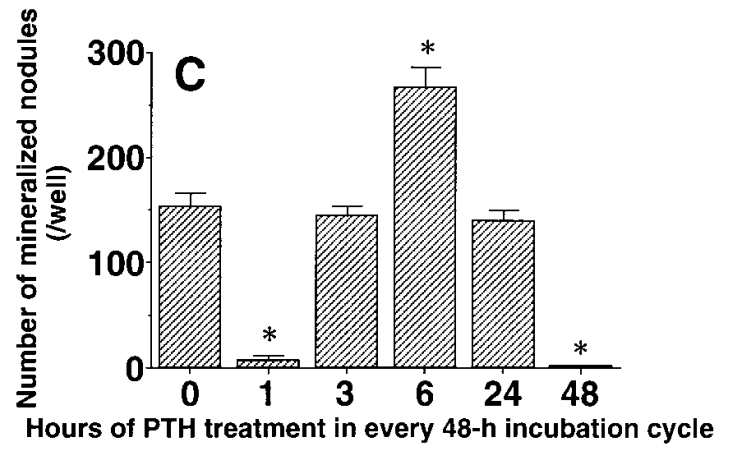

Figure 2. Effects of intermittent and continuous exposure to PTH on ALP activity, calcium content in the cell layer, and the number of bone nodules. Osteoblastic cells in a well of 6-well plates were exposed to PTH for various times in each 48-h incubation cycle as described in Methods. After repeating this cycle eight times, ALP activity $(A)$ and calcium content $(B)$ in the cell layer and the number of bone nodules $(C)$ were measured as described in Methods. Data are means \pm SD of $\operatorname{six}(A$ and $B)$ or four cultures $(C)$. ${ }^{*} P<0.01$ compared with the 0 -h value.

ated very low calcium content compared with that in the control group. The intermittent 6-h exposure group showed significantly higher calcium content than the control group on days 13-21. The cells continuously exposed to PTH accumulated extremely low levels of calcium in the cell layer throughout the culture period.

Dose-dependent effects of intermittent and continuous exposure to PTH on ALP activity are shown in Fig. 4. The stimulatory effect of 6-h intermittent exposure on ALP activity was recognized at concentrations higher than $0.05 \mathrm{ng} / \mathrm{ml}$, but the inhibitory effects of PTH on ALP activity induced by the 1-h and continuous exposures were evident at concentrations over $0.5 \mathrm{ng} / \mathrm{ml}$.

Fig. 5 shows the effects of the intermittent and continuous exposures to PTH on the levels of expression of mRNAs for ALP, osteocalcin, procollagen $\alpha 1(\mathrm{I})$, and $\mathrm{PTH} / \mathrm{PTHrP}$ recep-
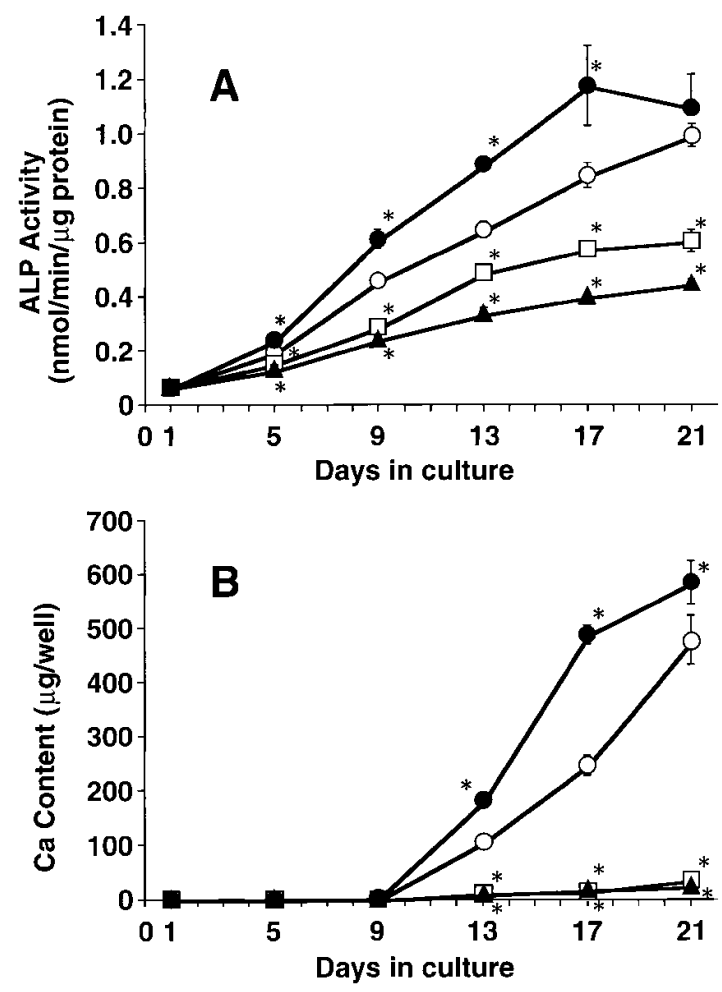

Figure 3. Time course of changes in ALP activity $(A)$ and calcium content $(B)$ in the cell layer induced by intermittent and continuous exposure to PTH. Osteoblastic cells were inoculated into a well of 6-well plates, and then exposed to PTH for various times in each 48-h incubation cycle as described in Methods. Changes in ALP activity and calcium content in the cell layer were measured every $4 \mathrm{~d}$ up to day 21. Control, $\bigcirc$; 1-h intermittent exposure, $\square$; 6-h intermittent exposure, $\mathbf{0}$; continuous exposure, $\boldsymbol{\Lambda}$. Data are means \pm SD of three cultures. $* P<0.01$ compared with the corresponding control cultures on each day examined.

tor. Intermittent exposure to PTH had diverse effects on the expression levels of these mRNAs. The 1-h exposure group showed decreased levels of ALP, osteocalcin, and PTH/ PTHrP receptor mRNA expression, but no apparent changes in procollagen $\alpha 1(\mathrm{I})$ mRNA expression compared with those in the control culture. In the 6-h exposure group, mRNA levels for ALP, osteocalcin, procollagen $\alpha 1(\mathrm{I})$, and PTH/PTHrP receptor were 3.4-, 9.4-, 1.6-, and 2.7-fold higher than those in the control culture, respectively. Continuous exposure to PTH apparently decreased expression of all these transcripts.

Changes in the amount of supplemented PTH during the culture period. The amount of immunoreactive PTH was not significantly decreased up to $72 \mathrm{~h}$ in the absence of the cells. When PTH was incubated in the presence of osteoblastic cells, however, the amounts of immunoreactive PTH gradually decreased after $6 \mathrm{~h}$. The residual amount of PTH was $100.8 \%$ at $1,99.5 \%$ at $3,84.9 \%$ at $6,74.8 \%$ at $12,53.8 \%$ at $24,36.0 \%$ at 48 , and $20.3 \%$ at $72 \mathrm{~h}$. The estimated amount of human PTH(1-34) at $48 \mathrm{~h}$ was $19 \mathrm{ng} / \mathrm{ml}$. This concentration was sufficient to show its effects as judged by the dose-dependent experiment shown in Fig. 4.

Signal transduction of the diverse action of intermittent or continuous PTH exposure on osteoblast differentiation. In most 


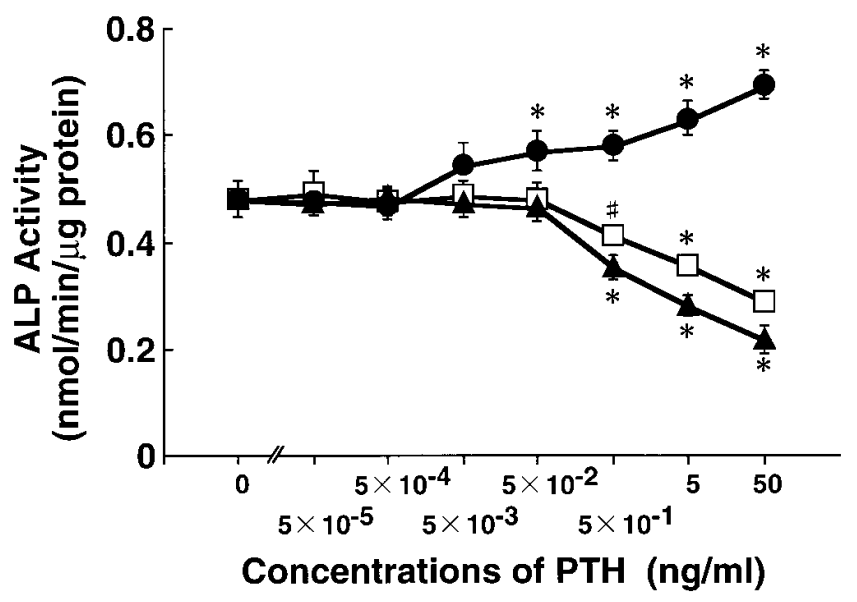

Figure 4. Dose-dependent effects of intermittent and continuous exposure to PTH on ALP activity in osteoblastic cells. Osteoblastic cells inoculated in a well of 6-well plates were exposed to graded concentrations of PTH intermittently or continuously in each 48-h incubation cycle. After repeating this cycle four times, ALP activity was measured as described in Methods. Control, $\bigcirc$; 1-h intermittent exposure, $\square$; 6-h intermittent exposure, $\mathbf{\bullet}$; continuous exposure, $\boldsymbol{\Lambda}$. Data are means \pm SD of three or four cultures. ${ }^{\sharp} P<0.05$ and ${ }^{*} P<0.01$ compared with the corresponding control cultures on each concentration examined.

of the experiments described above, cells were exposed to PTH for 16 or $20 \mathrm{~d}$ from the growth phase to the postconfluent phase. Since this exposure period was too long to investigate the signal transduction system using various inhibitors and stimulators, we next examined how many 48 -h incubation cycles of intermittent or continuous exposure were necessary for induction of similar inhibitory or stimulatory effects of PTH (Table I). When PTH exposure was initiated at a postconfluent state (day 5), only two 48-h incubation cycles were sufficient to mimic the changes in ALP activity induced by four cycles of treatment starting at day 1. In the postconfluent protocol, 1-h intermittent exposure and the continuous exposure to $\mathrm{PTH}$ similarly inhibited ALP activity, while 6-h intermittent exposure showed a stimulatory effect. PTH exposure starting at day

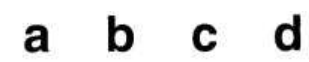

ALP

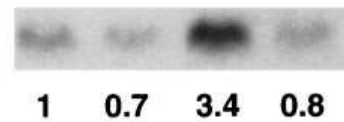

Osteocalcin

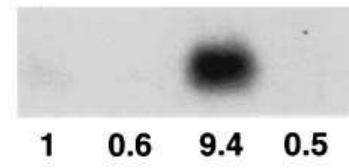

Procollagen $\alpha 1(\mathrm{I})$

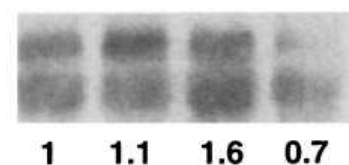

\section{PTH/PTHrP receptor}

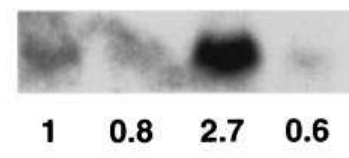

\section{$\beta$-tubulin}

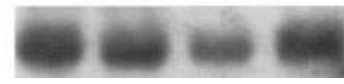

Figure 5. Effects of intermittent or continuous exposure to PTH on the expression of ALP, osteocalcin, procollagen $\alpha 1(\mathrm{I}), \mathrm{PTH} / \mathrm{PTHrP}$ receptor, and $\beta$-tubulin mRNAs. Osteoblastic cells inoculated in 10 -cm dishes were exposed to $50 \mathrm{ng} / \mathrm{ml} \mathrm{PTH} \mathrm{intermittently} \mathrm{(lanes} b$ and $c$ ) or continuously (lane $d$ ). The cells were exposed to PTH for the first 1 (lane $b$ ) or 6 (lane $c$ ) $\mathrm{h}$ in each 48 -h incubation cycle, and this cycle was repeated six times. Lane $a$ shows the control group. The mRNA levels were compared with that of $\beta$-tubulin. The number shown below each signal indicates the ratio of the expression level between the respective mRNA and $\beta$-tubulin mRNA compared with those in the control culture.

5 induced similar changes in ALP activity and calcium content in the cell layer measured on day 17 as in the cells treated with PTH starting at day 1 . These results suggest that only two 48 -h incubation cycles starting at a postconfluent state are sufficient for investigation of the mechanism underlying the diverse effects of PTH, depending on the mode of treatment.

Table I. Effects of PTH Exposure at a Postconfluent State of Osteoblastic Cells

\begin{tabular}{|c|c|c|c|c|c|}
\hline \multirow[b]{2}{*}{ Treatment } & \multirow[b]{2}{*}{ Days in culture } & \multicolumn{3}{|c|}{ ALP activity (nmol/min per $\mu \mathrm{g}$ protein) } & \multirow{2}{*}{$\begin{array}{c}\begin{array}{c}\text { Calcium content } \\
(\mu \mathrm{g} / \text { well })\end{array} \\
17 \mathrm{~d}\end{array}$} \\
\hline & & $5 \mathrm{~d}$ & $9 \mathrm{~d}$ & $17 \mathrm{~d}$ & \\
\hline \multirow[t]{4}{*}{ A } & Vehicle & $0.21 \pm 0.01$ & $0.43 \pm 0.02$ & $0.83 \pm 0.04$ & $223.6 \pm 8.0$ \\
\hline & 1-h intermittent exposure to PTH & $0.17 \pm 0.01 *$ & $0.32 \pm 0.02 *$ & $0.53 \pm 0.02 *$ & $30.9 \pm 5.9 *$ \\
\hline & 6-h intermittent exposure to PTH & $0.24 \pm 0.01 *$ & $0.62 \pm 0.01 *$ & $1.00 \pm 0.07^{*}$ & $407.1 \pm 21.7 *$ \\
\hline & Continuous exposure to $\mathrm{PTH}$ & $0.14 \pm 0.01 *$ & $0.22 \pm 0.01 *$ & $0.38 \pm 0.02 *$ & $22.9 \pm 2.4 *$ \\
\hline \multirow[t]{3}{*}{ B } & Vehicle $\rightarrow 1$-h intermittent exposure to PTH & & $0.34 \pm 0.03 *$ & $0.54 \pm 0.02 *$ & $30.9 \pm 5.4^{*}$ \\
\hline & Vehicle $\rightarrow 6$-h intermittent exposure to PTH & & $0.60 \pm 0.02 *$ & $1.03 \pm 0.05^{*}$ & $407.7 \pm 17.4^{*}$ \\
\hline & Vehicle $\rightarrow$ Continuous exposure to PTH & & $0.25 \pm 0.02 *$ & $0.39 \pm 0.02 *$ & $22.9 \pm 5.8^{*}$ \\
\hline
\end{tabular}

Osteoblastic cells inoculated into a well of 6-well plates were exposed to PTH intermittently or continuously in each 48-h incubation cycle on day 1 (A) or day 5 (B). In this culture system, the cells reached a confluent state on day 4 . The cells exposed to PTH starting on day 5 (B) were cultured without PTH until addition of the hormone. ALP activity and calcium content in the cell layer were measured on the indicated days as described in Methods. Data are means \pm SEM of five cultures. ${ }^{*} P<0.01$ compared with the corresponding control groups cultured with vehicle on each day. 


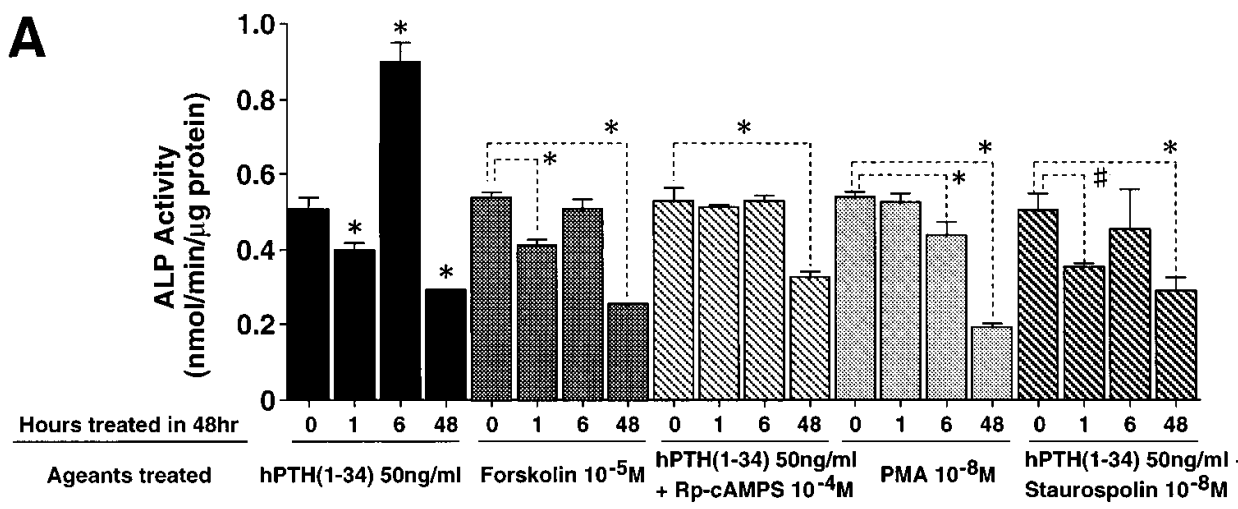

B

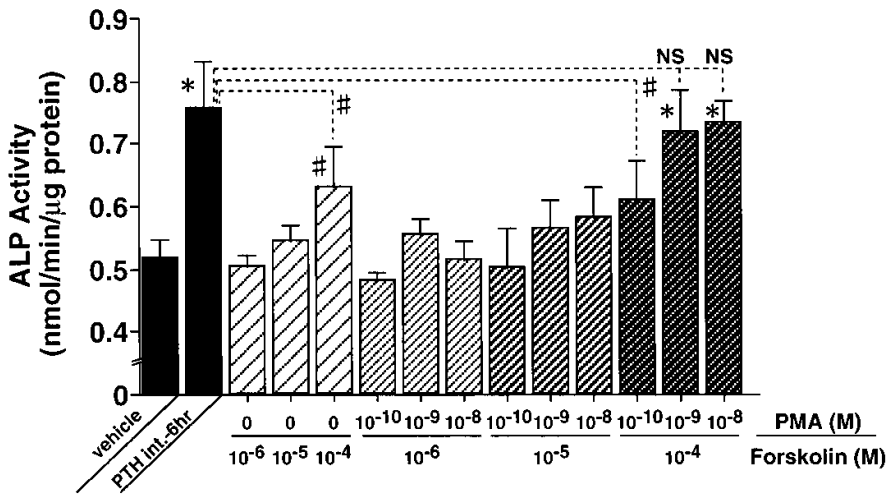

Figure 6. Effects of stimulators and inhibitors of CAMP/PKA and $\mathrm{Ca}^{2+} / \mathrm{PKC}$ on the ALP activity. Osteoblastic cells inoculated in a well of 6-well plates were cultured for $5 \mathrm{~d}$. They were exposed twice to the indicated reagents intermittently or continuously in each 48-h incubation cycle $(A)$. The osteoblastic cells were exposed twice to various concentrations of PMA and/or forskolin for the first $6 \mathrm{~h}$ in each 48-h incubation cycle $(B)$. ALP activity was measured as described in Methods. PTH int.-6 hr, 6-h intermittent exposure to PTH. Data are means \pm SD of four to six cultures. ${ }^{\#} P<0.05$ and $* P<0.01$ compared with the control culture without any additional reagents. ${ }^{\star} P<0.05$ and ${ }^{\S} P<0.01$ between the two groups connected with the dotted lines.
Using this experimental protocol, we measured the ALP activity and the expression levels of osteocalcin mRNA to investigate whether the signal transduction systems of cAMP/ PKA and $\mathrm{Ca}^{2+} / \mathrm{PKC}$ are involved in the diverse actions of PTH (Figs. 6 and 7). A 1-h exposure to forskolin, a stimulator of cAMP/PKA, inhibited ALP activity (Fig. $6 A$ ) and the expression level of osteocalcin mRNA (Fig. $7 A$ ) to the same extent as a 1-h exposure to PTH. In addition, Rp-cAMPS, a competitive inhibitor of cAMP, antagonized the inhibitory effect of PTH on the ALP activity (Fig. $6 A$ ) and the expression of osteocalcin mRNA (Fig. $7 A$ ) induced by a 1-h intermittent exposure. In contrast, the 1-h intermittent exposure to PMA, a stimulator of $\mathrm{Ca}^{2+} / \mathrm{PKC}$, induced no significant change in the ALP activity (Fig. $6 A$ ) and the expression of osteocalcin mRNA (Fig. $7 A$ ), compared with the control group. Staurosporin, an inhibitor of $\mathrm{Ca}^{2+} / \mathrm{PKC}$ and cAMP/PKA, caused no significant change in the inhibitory effect on the ALP activity (Fig. $6 \mathrm{~A}$ ) and the expression of osteocalcin mRNA (Fig. $7 \mathrm{~A}$ ) induced by a 1-h intermittent exposure to PTH.

6-h intermittent exposure to forskolin or PMA failed to mimic the stimulatory effect on the ALP activity (Fig. 6A) and the expression of osteocalcin mRNA (Fig. $7 A$ ) of PTH applied in the same manner. Addition of either Rp-cAMPS or Staurosporin completely blocked the stimulatory effects of the 6-h intermittent exposure to PTH on the ALP activity (Fig. 6A) and the expression of osteocalcin mRNA (Fig. $7 A$ ). These results suggest that cAMP/PKA and $\mathrm{Ca}^{2+} / \mathrm{PKC}$ are cooperatively involved in the stimulatory effect on the ALP activity and the expression of osteocalcin mRNA induced by the 6-h intermittent exposure to PTH.

We examined further whether forskolin and PMA have synergistic effects on the ALP activity and the expression of osteocalcin mRNA in the 6-h intermittent exposure group (Figs. $6 \mathrm{~B}$ and $7 \mathrm{~B})$. A high concentration $\left(10^{-4} \mathrm{M}\right)$ of forskolin increased ALP activity, but it failed to reach the same extent as the enzyme activity induced by 6-h intermittent exposure to PTH. A high concentration $\left(10^{-8} \mathrm{M}\right)$ of PMA inhibited ALP activity (Fig. $6 \mathrm{C}$ ), but lower concentrations $\left(10^{-9}\right.$ and $\left.10^{-10} \mathrm{M}\right)$ of PMA had no significant effects (data not shown). Simultaneous treatment with forskolin at concentrations lower than $10^{-5} \mathrm{M}$ and various concentrations of PMA induced no significant changes in ALP activity, whereas simultaneous exposure to high concentrations of forskolin $\left(10^{-4} \mathrm{M}\right)$ and PMA $\left(10^{-9}\right.$ and $10^{-8} \mathrm{M}$ ) significantly stimulated not only ALP activity, but also the expression of osteocalcin mRNA to the same extent as that induced by the 6-h intermittent exposure to PTH (Figs. 6 $B$ and $7 B$ ).

Continuous exposure to forskolin or PMA strongly inhibited the ALP activity (Fig. $6 A$ ) and the expression of osteocalcin mRNA (Fig. $7 A$ ) to the same extent as continuous exposure to PTH. Adding either Rp-cAMPS or Staurosporin failed to block the inhibitory effect of continuous exposure to PTH on ALP activity (Fig. $6 A$ ) and the expression of osteocalcin mRNA (Fig. $7 A$ ).

Effects of anti-IGF-I antibody. Several lines of evidence have indicated that IGF-I is involved in the anabolic action of PTH on the proliferation and differentiation of osteoblasts. Therefore, we investigated the role of IGF-I in PTH-induced ALP activity and expression of osteocalcin mRNA using a neutralizing antibody (Fig. $8, A$ and $B$ ). In the control culture, the IGF-I antibody induced no significant changes in the ALP activity and the expression of osteocalcin mRNA at any con- 


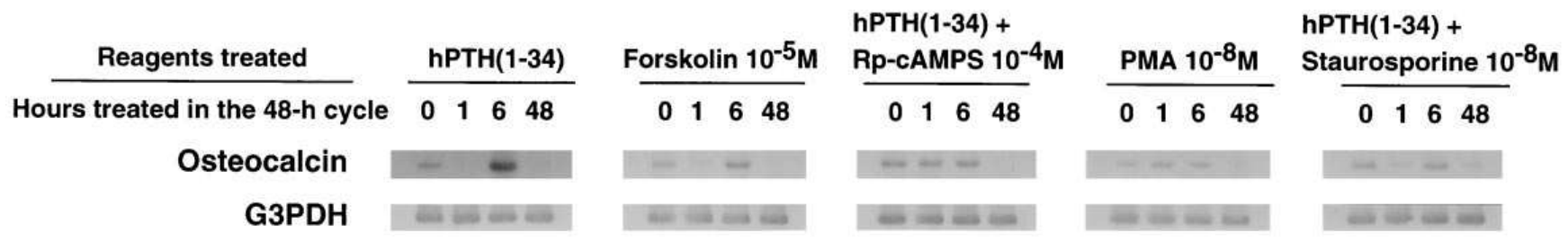

B

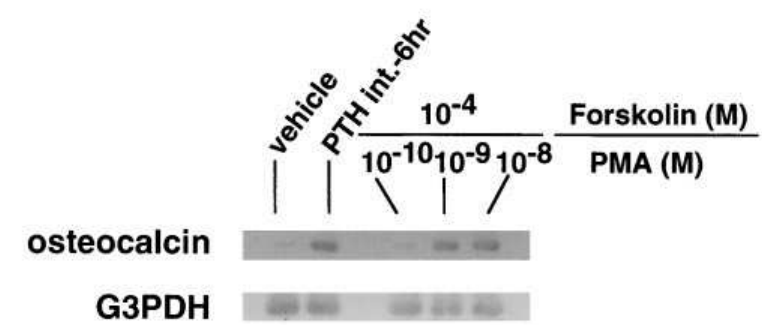

Figure 7. Effects of stimulators and inhibitors of cAMP/PKA and $\mathrm{Ca}^{2+} / \mathrm{PKC}$ on the expression of osteocalcin mRNA. Osteoblastic cells inoculated in a well of 6-well plates were cultured for $5 \mathrm{~d}$. They were exposed twice to the indicated reagents intermittently or continuously in each 48 -h incubation cycle $(A)$. The osteoblastic cells were exposed twice to various concentrations of PMA and/or forskolin for the first $6 \mathrm{~h}$ in each 48 -h incubation cycle $(B)$. The expression of osteocalcin mRNA and G3PDH mRNA was determined as described in Methods. PTH int.-6, 6-h intermittent exposure to PTH.

centrations examined. Adding the antibody dose dependently inhibited both the ALP activity and the expression of osteocalcin mRNA induced by the 6-h exposure to PTH. The maximum concentration of the antibody used $(80 \mu \mathrm{g} / \mathrm{ml})$ reduced the levels of ALP activity and the expression of osteocalcin mRNA to those in the control culture. Addition of the antibody induced no significant change in the ALP activity or the expression of osteocalcin mRNA induced by the 1-h exposure to PTH.

\section{Discussion}

In the present study, we examined the in vitro effects of continuous and intermittent exposure to PTH on differentiation of osteoblastic cells isolated from calvariae of newborn rats to investigate the mechanism of action of PTH on bone formation that varies with the mode of administration in vivo. Continuous exposure to PTH strongly inhibited osteoblast differentiation by suppressing ALP activity, expression of ALP, osteocalcin, and procollagen $\alpha 1$ (I) mRNAs and the formation of bone nodules. These results support the previous observation that continuous exposure to PTH inhibited osteoblast differentiation in various cells. Intermittent exposure to PTH in each 48-h incubation cycle exerted disparate effects on these phenotypes depending on the period of exposure. When osteoblasts were exposed intermittently to PTH only for the first hour of each 48-h incubation cycle, ALP activity, expression of ALP and osteocalcin mRNAs, and the formation of bone nodules were similarly inhibited compared with those in the control cells. However, when osteoblasts were exposed to PTH intermit- tently for the first $6 \mathrm{~h}$ of each 48-h incubation cycle, these parameters were significantly increased. On the other hand, intermittent exposure to PTH for the first 3 or $24 \mathrm{~h}$ of each 48 -h cycle induced no significant increase in the phenotype. These results indicate that the action of PTH on osteoblast differentiation differs depending on the exposure time to the hormone in vitro.

We reported that intermittent injection of PTH into normal rats increased the number of ALP-positive colony forming unit-fibroblastic (CFU-F) in bone marrow (31). We also reported that the continuous exposure to PTH stimulated osteoblast differentiation in immature osteoblasts, but inhibited it in more mature cells during the differentiation of osteoblastic cells isolated from calvariae of newborn mice (28). These results suggest that the anabolic effect of PTH can be explained at least in part by the stimulation of proliferation and differentiation of osteoprogenitor cells. Bellows et al. (25) demonstrated that the continuous exposure to PTH inhibited bone nodule formation in osteoblastic cells isolated from calvariae of embryonic rats. The inhibitory effect of PTH occurred at a late stage in the differentiation of osteoprogenitor cells, probably preventing differentiation of preosteoblasts into osteoblasts (25). In addition, Dobnig and Turner (6) recently reported the possibility that the increased osteoblast number and bone formation by intermittent injection of PTH were due to the activation of preexisting bone lining cells to osteoblasts, but not the stimulation of proliferation of osteoprogenitor cells. Thus, the target stage of PTH action during osteoblast differentiation has not been fully clarified. To elucidate this, we investigated the effects of various modes of PTH exposure 


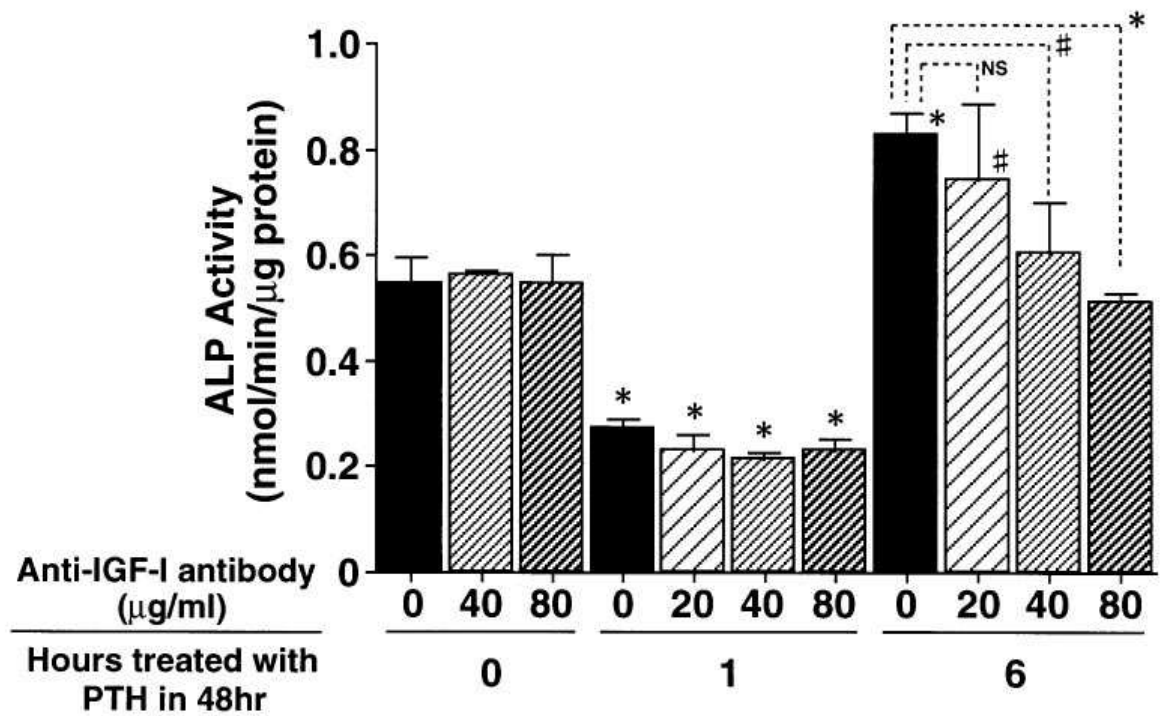

B

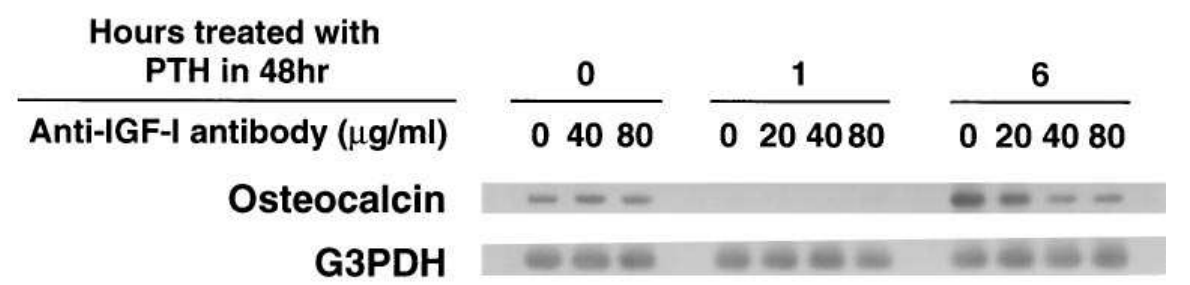

Figure 8. The effects of neutralizing antibody against IGF-I on the ALP activity and the expression of osteocalcin mRNA induced by intermittent exposure to PTH. Osteoblastic cells inoculated in a well of 12-well plates were cultured for $5 \mathrm{~d}$, and then the cells were exposed to PTH $(50 \mathrm{ng} / \mathrm{ml})$ intermittently in each 48-h incubation cycle. This cycle was repeated twice in the presence and absence of various concentrations of neutralizing antibody against IGF-I. The antibody was present during the entire experimental period. The ALP activity and the expression of osteocalcin mRNA were measured as described in Methods. Data are means \pm SD of three cultures. ${ }^{\#} P<0.05$ and * $P<0.01$ compared with the values in the control culture without PTH and IGF-I antibody. ${ }^{\star} P<0.05$ and ${ }^{\S} P<0.01$ between the two groups connected with the dotted lines. on the differentiation of osteoblastic cells isolated from newborn rat calvariae, because these cells showed the diversity of stages of osteoblast differentiation from immature to mature osteoblasts according to the period in culture. Time course analysis showed that both the stimulatory effect on ALP activity by 6 -h intermittent exposure to PTH and the inhibitory effects of 1-h intermittent and continuous exposure to the hormone occurred from the growth phase, and the effects became more apparent at the postconfluent phase. In addition, the differences between inhibitory and stimulatory effects induced by various modes of PTH exposure were more conspicuous in the number of bone nodules, calcium content in the cell layer, and expression of osteocalcin mRNA, which reflected terminal differentiation of osteoblasts, than that in ALP activity. These results suggest that the diverse action of PTH induced by the different exposure times occurs at various stages of osteoblast differentiation, but it is more prominent in mature than immature osteoblasts. This may be related to $\mathrm{PTH} / \mathrm{PTHrP}$ receptor expression levels, since levels of this transcript increased with time in culture in the osteoblastic cells used in this study (data not shown). The recent reports by Lee and co-workers (32, 33), in which they demonstrated by in situ hybridization a high level of PTH/PTHrP receptor mRNA expression in osteoblasts covering the bone surface, supports this working hypothesis.

Exposure to PTH induces downregulation of its receptor in the target cells $(34,35)$. In the present study, we demonstrated that the expression level of PTH/PTHrP receptor mRNA was differently regulated by repeating the intermittent and continuous exposure of PTH; 1-h intermittent exposure showed a slight decrease, 6-h intermittent exposure showed a marked increase, and continuous exposure showed a marked decrease in the expression of PTH/PTHrP receptor mRNA. When PTH was added to osteoblastic cells in a postconfluent state, similar changes of the level of PTH/PTHrP receptor mRNA expression were observed; the level of $\mathrm{PTH} / \mathrm{PTHrP}$ receptor mRNA expression was first downregulated $2 \mathrm{~h}$ after $\mathrm{PTH}$ exposure, followed by a marked upregulation from 4 to $8 \mathrm{~h}$ after exposure, and it was apparently downregulated at $48 \mathrm{~h}$ after the continuous exposure (data not shown). These changes may be closely related to the mechanism of the diverse action of PTH. It is important to characterize the nature of $\mathrm{PTH} / \mathrm{PTHrP}$ receptor including its affinity and binding capacity to the ligand.

It is possible to speculate that the diverse action of PTH might be due to degradation of the hormone during the culture. To address this issue, the stability of PTH during culture was estimated by measuring the residual amounts of the hormone. The residual amount of PTH(1-34) in the culture media $48 \mathrm{~h}$ after its addition was sufficient for its effects as judged by the dose-response study. This suggests that the disparate effects of PTH induced by the different exposure times were due to the direct action of the hormone, and not to degradation of the hormone during culture.

The diverse action of PTH induced by the different exposure times might be caused by differences in intracellular signaling mechanisms, since cross talk between the two signal transduction systems, cAMP/PKA and $\mathrm{Ca}^{2+} / \mathrm{PKC}$, occurs in osteoblasts after PTH stimulation $(20,36,37)$. To confirm this, we conducted experiments using stimulators and inhibitors of cAMP/PKA and $\mathrm{Ca}^{2+} / \mathrm{PKC}$. Intermittent 1-h exposure to for- 
skolin mimicked the inhibitory effect on the ALP activity and the expression of osteocalcin mRNA induced by intermittent exposure to PTH with the same time schedule. In addition, Rp-cAMPS completely blocked the inhibitory effect of PTH on the ALP activity and the expression of osteocalcin mRNA induced by 1-h intermittent exposure. In contrast, PMA failed to mimic the inhibitory effect on ALP activity and the expression of osteocalcin mRNA by the 1-h intermittent exposure, and Staurosporin could not block the inhibition of the ALP activity and the expression of osteocalcin mRNA by 1-h intermittent exposure to PTH. These results indicate that cAMP/ PKA is the major signal transduction system involved in the inhibitory effect of 1-h intermittent exposure to PTH. Intermittent exposure for $6 \mathrm{~h}$ to either forskolin or PMA failed to mimic the stimulatory effect on ALP activity and the expression of osteocalcin mRNA induced by 6-h intermittent exposure to PTH, but the simultaneous addition of forskolin $\left(10^{-4} \mathrm{M}\right)$ and PMA $\left(10^{-9}-10^{-8} \mathrm{M}\right)$ stimulated the ALP activity and the expression of osteocalcin mRNA to the same extent as that induced by the 6-h intermittent exposure to PTH. In addition, the stimulatory effect of 6-h intermittent exposure to PTH was almost completely blocked by either Rp-cAMPS or Staurosporin. These results suggest that independent activation of either cAMP/PKA or $\mathrm{Ca}^{2+} / \mathrm{PKC}$ is not sufficient to induce the anabolic effect of 6-h intermittent exposure to PTH, and that both cAMP/PKA and $\mathrm{Ca}^{2+} / \mathrm{PKC}$ are cooperatively involved in the mechanism of this effect. Continuous exposure to forskolin or PMA mimicked the inhibitory effect on the ALP activity and the expression of osteocalcin mRNA induced by continuous exposure to PTH, but the addition of Rp-cAMPS or Staurosporin failed to block this inhibitory effect of PTH. These results suggest that both $\mathrm{cAMP} / \mathrm{PKA}$ and $\mathrm{Ca}^{2+} / \mathrm{PKC}$ signal transduction systems are involved in the inhibitory action of continuous exposure to PTH, but they act independently on its inhibitory effect. Turksen et al. (38) reported that forskolin had a biphasic effect on the formation of bone nodules in a culture system similar to that used in the present study; the continuous exposure or the repeated short term exposure $(1 \mathrm{~h} \mathrm{ev}-$ ery $2 \mathrm{~d}$ for $21 \mathrm{~d})$ to a high concentration of forskolin $\left(10^{-5} \mathrm{M}\right)$ significantly inhibited the formation of bone nodules, but the exposure to a low concentration of forskolin $\left(10^{-9} \mathrm{M}\right)$ stimulated it. They also suggested that the former inhibitory effect was mediated by an increased level of intracellular cAMP, but the latter stimulatory effect was evoked by a mechanism different from the cAMP-dependent process (38). These results are consistent with our findings that cAMP/PKA signaling may inhibit the formation of bone nodules, when it does not act cooperatively with a $\mathrm{Ca}^{2+} / \mathrm{PKC}$ signaling. Thus, the diverse action of PTH, depending on the exposure time, may be caused by the different usage of the signal transduction systems with PTH stimulation.

Scutt et al. (20) reported that short term (5- to 30-min) PTH treatment stimulated cell proliferation of osteoblasts isolated from chicken calvariae, compared with long term treatment with the hormone. They suggested that the stimulation of cell proliferation induced by the short term PTH treatment was due to selective regulation by cAMP/PKA. Their findings may be related to the suppression of osteoblast differentiation induced by the 1-h intermittent exposure to PTH in our experiment, in which cAMP/PKA was also a major signal transduction pathway. Since the suppression of ALP activity by 1-h intermittent exposure to PTH was blocked when the treatment was conducted in the presence of hydroxyurea (data not shown), this PTH action might be due to the stimulation of cell proliferation with the hormone through activation of cAMP/ PKA. In contrast, the stimulatory effect on the ALP activity induced by 6-h intermittent exposure to $\mathrm{PTH}$ was reproduced even in the presence of hydroxyurea (data not shown). This suggests that mechanisms other than cell proliferation are involved in the stimulatory effect of the 6-h intermittent exposure to PTH. One of the candidates involved in this mechanism is IGF-I.

Hock et al. reported that the stimulation of osteoblast differentiation by IGF-I occurs even in the presence of hydroxyurea (39). Several reports suggested that the anabolic action of PTH in bone is mediated by IGF-I (40-43). In our study, the stimulation of the ALP activity and the expression of osteocalcin mRNA by 6-h intermittent exposure to PTH were almost completely inhibited by addition of a neutralizing antibody against IGF-I, although the inhibition of the ALP activity and the expression of osteocalcin mRNA by the 1-h intermittent exposure to PTH was not affected by this antibody. Continuous exposure of IGF-I (100 nM) induced a significant increase in the number of bone nodules in osteoblastic cells used in the present study (unpublished observation). In addition, Watson et al. demonstrated by an in situ hybridization technique that the expression of IGF-I mRNA was increased in bone of PTHtreated animals (44). Taken together, the anabolic effects of PTH on bone formation involves, at least in part, the action of IGF-I. Since the action of IGF-I is regulated by a complicated mechanism including interactions with IGF-I, IGF-I receptors, IGF-I binding proteins (IGFBPs) and IGFBP proteases, further studies are necessary to determine conclusively the role of IGF-I in the action of PTH.

In conclusion, PTH exerts diverse effects on osteoblast differentiation depending on the time schedule of exposure to the hormone in vitro. The present in vitro study provides insight into the mechanism of the diverse action of PTH in bone in vivo.

\section{Acknowledgments}

This work was supported in part by grants-in-aid from the Ministry of Science, Education, and Culture of Japan. Toshinori Ishizuya has been awarded the Young Investigator Award of the Japanese Society of Bone Morphometry.

\section{References}

1. Bauer, E., J. Aub, and F. Algright. 1929. Studies of calcium and phosphorus metabolism. V. A study of the bone trabeculae as a readily available reserve supply of calcium. J. Exp. Med. 49:145-162.

2. Reeve, J., D. Williams, R. Hesp, P. Hulme, J. Klenerman, J.M. Zanelli, A.J. Darby, G.W. Tregear, and J.A. Parsons. 1976. Anabolic effects of low doses of a fragment of human parathyroid hormone on the skeleton in postmenopausal osteoporosis. Lancet. i:1035-1038.

3. Hori, M., T. Uzawa, K. Morita, T. Noda, H. Takahashi, and J. Inoue. 1988. Effect of human parathyroid hormone (PTH(1-34)) on experimental osteopenia of rats induced by ovariectomy. Bone Miner. 3:193-199.

4. Wronski, T.J., C.F. Yen, H. Qi, and L.M. Dann. 1993. Parathyroid hormone is more effective than estrogen or bisphosphonates for restoration of lost bone mass in ovariectomized rats. Endocrinology. 132:823-831.

5. Wronski, T.J., and C.F. Yen. 1994. Anabolic effects of parathyroid hormone on cortical bone in ovariectomized rats. Bone (NY). 15:51-58.

6. Dobnig, H., and R.T. Turner. 1995. Evidence that intermittent treatment with parathyroid hormone increases bone formation in adult rats by activation of bone lining cells. Endocrinology. 136:3632-3638.

7. Meng, X.W., X.G. Liang, R. Birchman, D.D. Wu, D.W. Dempster, R. Lindsay, and V. Shen. 1996. Temporal expression of the anabolic action of PTH 
in cancellous bone of ovariectomized rats. J. Bone Miner. Res. 11:421-429.

8. Tam, C.S., J.N.M. Heersche, T.M. Murray, and J.A. Parsons. 1982. Parathyroid hormone stimulates the bone apposition rate independently of its resorptive action: differential effects of intermittent and continuous administration. Endocrinology. 110:516-512.

9. Podbesek, R., C. Edouard, P.J. Meunier, J.A. Parsons, J. Reeve, R.W. Stevenson, and J.M. Zanelli. 1983. Effects of two treatment regimes with synthetic human parathyroid hormone fragment on bone formation and the tissue balance of trabecular bone in greyhounds. Endocrinology. 112:1000-1006.

10. Uzawa, T., M. Hori, S. Ejiri, and H. Ozawa. 1995. Comparison of the effects of intermittent and continuous administration of human parathyroid hormone (1-34) on rat bone. Bone. 16:477-484

11. Wong, G. 1990. Isolation and behavior of isolated bone-forming cells. In The Osteoblast and Osteocytes. Vol 1. K. Hall, editor. The Telford Press, Caldwell, NJ. 171-192.

12. Aubin, J.E., K. Turksen, and J.N.M. Heersche. 1993. Osteoblastic lineage. In Cellular and Molecular Biology of Bone. M. Noda, editor. Academic Press, Inc., London. 1-45.

13. Partridge, N.G., D. Alcorn, V.P. Michelangeli, B.E. Kemp, G.B. Ryan, and T.J. Martin. 1981. Functional properties of hormonally responsive cultured normal and malignant rat osteoblastic cells. Endocrinology. 108:213-219.

14. Majeska, R.J., S.B. Rodan, and G.A. Rodan. 1978. Maintenance of parathyroid hormone response in clonal rat osteosarcoma cell lines. Exp. Cell Res. 111:465-468.

15. Sudo, H., H. Kodama, Y. Amagai, S. Yamamoto, and S. Kasai. 1983. In vitro differentiation and calcification in a new clonal osteogenic cell line derived from newborn calvaria. J. Cell Biol. 96:191-198.

16. Yamaguchi, A., and A.J. Kahn. 1991. Clonal osteoblastic cell lines express myogenic and adipocytic developmental potential. Calcif. Tissue Int. 49: $221-225$

17. Stein, G.S., A.J.V. Wijnen, J.L. Stein, J.B. Lian, J.P. Bidwell, and M. Montecino. 1994. Nuclear architecture supports integration of physiological regulatory signals for transcription of cell growth and tissue-specific genes during osteoblast differentiation. J. Cell. Biochem. 55:4-15.

18. Bellows, C.G., J.E. Aubin, J.N.M. Heersche, and M.E. Antosez. 1986. Mineralized bone nodules formed in vitro from enzymatically released rat calvaria cell populations. Calcif. Tissue Int. 36:143-154.

19. MacDonald, B.R., J.A. Gallagher, and R.G.G. Russell. 1986. Parathyroid hormone stimulated the proliferation of cells derived from human bone. Endocrinology. 118:2445-2449.

20. Scutt, A., C. Duvos, J. Lauber, and H. Mayer. 1994. Time-dependent effects of parathyroid hormone and prostaglandin E2 on DNA synthesis by periosteal cells from embryonic chick calvaria. Calcif. Tissue Int. 55:208-215.

21. Partridge, N.C., A.L. Opie, R.T. Opie, and T.J. Martin. 1985. Inhibitory effects of parathyroid hormone on growth of osteogenic sarcoma cells. Calcif. Tissue Int. 37:519-525.

22. Kano, J., T. Sugimoto, M. Fukase, and K. Chihara. 1993. Cross talk of dual-signal transduction systems in the regulation of DNA synthesis by parathyroid hormone in osteoblastic osteosarcoma cells. J. Bone Miner. Res. 8:323-329.

23. Majeska, R.J., and G.A. Rodan. 1982. Alkaline phosphatase inhibition by parathyroid hormone and isoproterenol in a clonal rat osteosarcoma cell line. Possible mediation by cyclic AMP. Calcif. Tissue Int. 34:59-66.

24. Nakatani, Y., M. Tunoi, Y. Hakeda, N. Kurihara, K. Fujita, and M. Kumegawa. 1984. Effects of parathyroid hormone on cAMP production and alkaline phosphatase activity in osteoblastic clone MC3T3-E1 cells. Biochem. Biophys. Res. Commun. 123:894-898.

25. Bellows, C.G., H. Ishida, J.E. Aubin, and J.N.M. Heersche. 1990. Parathyroid hormone reversibly suppresses the differentiation of osteoprogenitor cells into functional osteoblasts. Endocrinology. 127:3111-3116.

26. Jongen, J.W.J.M., M.P. Bos, J.M.V.D. Meer, and M.P.M. HerrmannErlee. 1993. Parathyroid hormone-induced changes in alkaline phosphatase expression in fetal calvarial osteoblasts: differences between rat and mouse. $J$. Cell. Physiol. 155:36-43.

27. Terakado, A., M. Tagawa, S. Goto, M. Yamazaki, H. Moriya, and S. Fujimura. 1995. Elevation of alkaline phosphatase activity induced by parathyroid hormone in osteoblastic cells from the spinal hyperostotic mouse TWY (twy/twy). Calcif. Tissue Int. 56:135-139.

28. Isogai, Y., T. Akatsu, T. Ishizuya, A. Yamaguchi, M. Hori, N. Takahashi, and T. Suda. 1996. Parathyroid hormone regulates osteoblast differentiation positively or negatively depending on the differentiation stages. J. Bone Miner. Res. 11:1384-1393.

29. Yokose, S., T. Ishizuya, T. Ikeda, T. Nakamura, H. Tsurukami, K. Kawasaki, T. Suda, S. Yoshiki, and A. Yamaguchi. 1996. An estrogen deficiency caused by ovariectomy increases plasma levels of systemic factors that stimulate proliferation and differentiation of osteoblasts in rats. Endocrinology. 137:469-478.

30. Katagiri, T., A. Yamaguchi, M. Komaki, E. Abe, N. Takahashi, T. Ikeda, V. Rosen, J.M. Wozny, A. Fujisawa-Sehara, and T. Suda. 1994. Bone morphogenetic protein-2 converts the differentiation pathway of $\mathrm{C} 2 \mathrm{C} 12$ myoblasts into the osteoblast lineage. J. Cell Biol. 127:1755-1766.

31. Nishida, S., A. Yamaguchi, T. Tanizawa, N. Endo, T. Mashiba, Y. Uchiyama, T. Suda, S. Yoshiki, and H.E. Takahashi. 1994. Increased bone formation by intermittent parathyroid hormone administration is due to the stimulation of proliferation and differentiation of osteoprogenitor cells in bone marrow. Bone (NY). 15:717-723.

32. Lee, K., J.D. Deeds, A.T. Bond, H. Jüpner, A.B. Abou-Samra, and G.V. Segre. 1993. In situ localization of PTH/PTHrP receptor mRNA in the bone of fetal and young rats. Bone (NY). 14:341-345.

33. Lee, K., J.D. Deeds, S. Chiba, M. Un-no, A.T. Bond, and G.V. Segre. 1994. Parathyroid hormone induces sequential c-fos expression in bone cells in vivo: in situ localization of its receptor and c-fos messenger ribonucleic acids. Endocrinology. 134:441-450.

34. Yamamoto, O., C. Shigeno, J.T. Potts, and G.V. Segre. 1988. Characterization and agonist-induced down-regulation of parathyroid hormone receptors in clonal osteosarcoma cells. Endocrinology. 122:1208-1217.

35. Fukuyama, S., E. Shipani, H. Jüpner, B. Lanske, H.M. Kronenberg, A.B. Abou-Samra, and F.R. Gringhurst. 1994. Role of protein kinase-A in homologous downregulation of parathyroid hormone (PTH)/PTH-related peptide receptor messenger ribonucleic acid in human osteoblast-like SaOS-2 cells. Endocrinology. 134:1851-1858.

36. Sugimoto, T., K. Ikeda, J. Kuno, T. Yamaguchi, M. Fukase, and K. Chihara. 1994. Cross-talk of parathyroid hormone-responsive dual signal transduc tion systems in osteoblastic osteosarcoma cells: its role in PTH-induced homologous desensitization of intracellular calcium response. J. Cell. Physiol. 158: 374-380.

37. Friedman, P.A., B.A. Coutermarsh, S.M. Kennedy, and F.A. Gesek, 1996. Parathyroid hormone stimulation of calcium transport is mediated by dual signaling mechanisms involving protein kinase $\mathrm{A}$ and protein kinase $\mathrm{C}$. Endocrinology. 137:13-20.

38. Turksen, K., A.E. Grigoriadis, J.N.M. Heersche, and J.E. Aubin. 1990. Forskolin has biphasic effects of osteoprogenitor cell differentiation in vitro. $J$. Cell. Physiol. 142:61-69.

39. Hock, J.M., M. Centrella, and E. Canalis. 1988. Insulin-like growth factor I has independent effects on bone matrix formation and cell replication. Endocrinology. 122:254-260.

40. Canalis, E., M. Centrella, W. Burch, and T.L. McCarthy. 1989. Insulinlike growth factor I mediates selective anabolic effects of parathyroid hormone in bone cultures. J. Clin. Invest. 83:60-65.

41. Linkhart, T.A., and S. Mohan. 1989. Parathyroid hormone stimulates release of insulin-like growth factor-I (IGF-I) and IGF-II from neonatal mouse calvaria in organ culture. Endocrinology. 125:1484-1491.

42. McCarthy, T.L., M. Centrella, and E. Canalis. 1989. Parathyroid hormone enhances the transcript and polypeptide levels of insulin-like growth factor I in osteoblast-enriched cultures from fetal rat bone. Endocrinology. 124: 1247-1253.

43. Pfeilschifter, J., F. Laukhuf, B. Müler-Beckmann, W.F. Blum, T. Pfister, and R. Ziegler. 1995. Parathyroid hormone increases the concentration of insulin-like growth factor-I and transforming growth factor beta 1 in rat bone. $J$. Clin. Invest. 96:767-774

44. Watson, P., D. Lazowski, V. Han, L. Fraher, B. Steer, and A. Hodsman. 1995. Parathyroid hormone restores bone mass and enhances osteoblast insulin-like growth factor I gene expression in ovariectomized rats. Bone $(N Y)$. 16: 357-365. 